\title{
SISTEM EKONOMI KAPITALISME DAVID RICHARDO, THOMAS \\ MALTUS DAN JB. SAY
}

Oleh : Nela Novyanti (90100118098)

\section{A. David Richardo}

David Ricardo adalah anak ketiga dari 23 bersaudara dari keluarga Yahudi yang bernama Abraham Israel Ricardo yang bekerja sebagai seorang pialang, dia lahir di London pada tahun 1772. Di usianya ke 51 tepat pada tahun 1823, David meninggal secara mendadak dikarenakan infeksi telinga. Dia meninggalkan seorang istri dan tujuh anak. Ricardo adalah seorang Pemikir yang paling menonjol di antara segenap pakar Mazhab Klasik. (Pujiati, 2011). Berikut beberapa pemikiran David Richardo. (Qomar \& Muna, 2020)

\section{Pemikiran Moneter David Ricardo}

Untuk menjaga stabilitas moneter suatu negara, David Ricardo berpendapat sistem moneter harus menggunakan "standar nilai tukar emas", artinya uang yang beredar di suatu negara baik dalam bentuk simpanan ataupun kredit dapat dikonversikan dengan harga emas yang sudah ditetepkan, dengan tujuan agar harga emas tetap sama nilainya dengan uang kertas (Bank Note)

2. Hukum Pendapatan Yang Menurun

Karya lain David Ricardo adalah tulisannya yang berjudul "Essay on the Influence of Low Price of Corn on the Profits of Stock" yang terbit pada tahun 1815 menuliskan hasil pemikiran Ricardo tentang kelangkaan tanah akan menurunkan pertumbuhan ekonomi.

3. Keunggulan Komparatif

Menurut David Richardo "perdagangan bebas akan menguntungkan kedua belah pihak, dan yang saling mengejutkan adalah perdagangan bebas akan membuat suatu negara melakukan spesialisasi 
meskipun suatu negara memiliki keuntungan absolut dalam produk tertentu" (Maiwan, 2015)

Maksud dari pendapat david adalah setiap negara memiliki paling tidak satu kegiatan produksi barang yang biayanya relative rendah sehingga mampu untuk bersaing dalam perdagangan internasional dan mengambil spesialisasi barang tersebut sehingga terjadi spesialisasi barang tiap Negara. Hal ini berbanding terbalik dengan hasil penelitian I'id Badry Sa'idy dalam jurnal analsisi daya saing komoditas tekstil dan produk tekstil Indonesia di Amerika Serikat yang menunjukkan bahwa perdagangan internasional justru mematikan perekonmian suatu Negara jka tidak mampu bersaing seperti Indonesia yang mengalami penurunan daya saing (Sa'idy, 2013)

\section{Distribusi Pendapatan, Bukan Pertumbuhan}

Perbedaan antara Smith dengan Ricardo adalah jika Smith berfokus pada pertumbuhan, maka Ricardo berfokus pada distribusi pendapatan. Menurut David bahwa kesejahteraan akan tercappai dengan distribusi pendapatan yang merata.

\section{Teori Upah Besi (Iron Wage Theory)}

Teori upah subsitensi (hukum besi) oleh David Ricardo yaitu upah ditentukan oleh interaksi penawaran dan permintaan akan buruh. Teori upah besi merupakan upah riil dalam jangka Panjang yang cenderung berpengaruh terhadap upah minimum yang diperlukan untuk menyokong kehidupan pekerja.

6. Teori Nilai Kerja

Tentang teori nilai kerja, Ricardo menjelaskan bahwa nilai tukar suatu barang ditentukan oleh ongkos yang perlu dikeluarkan untuk menghasilkan suatu barang.

7. Teori Sewa Tanah

Menurut richardo Seandainya tanah berlimpah ruah jumlahnya seperti halnya udara, maka setiap orang dapat memiliki tanah sehingga pasti tidak ada harganya. Tanah akan menjadi "barang bebas". Temuan 
David ini benar-benar terbukti hingga saat ini bahkan banyak Ahli ekonomi menggunakan penalaran David hari ini untuk menjelaskan mengapa pertanian yang cukup menghasilkan banyak keuntungan tidak membantu mensejahterakan petani tetapi justru membuat pemilik lahanlah yang semakin kaya. (Priyono \& Ismali, 2012)

\section{B. Thomas Maltus}

Thomas Robert Malthus, FRS (lahir di Surrey, Inggris, 13 Februari 1766 meninggal di Haileybury, Hertford, Inggris, 29 Desember 1834 pada umur 68 tahun), yang biasanya dikenal sebagai Thomas Malthus, meskipun ia lebih suka dipanggil "Robert Malthus". (Qomar \& Muna, 2020). Mulanya Malthus tak lebih dari seorang pendeta yang sama sekali tak dikenal. Tetapi tahun 1798, Malthus itu terbitkan sebuah buku walau tipis namun sangat berpengaruh. Judulnya An Essay on the Principle of Population as it Affects the Future Improvement of Society. (Subair, 2015) Pola dasar pemikiran Malthus dan kerangka analisisnya ialah menyangkut teori tentang sewa tanah dan teori tentang penduduk. Kelahiran yang tidak terkontrol menyebabkan penduduk bertambah menurut deret ukur padahal persediaan bahan makanan bertambah secara deret hitung. (Pujiati, 2011)

Malthus berpendapat bahwa tingkat pendapatan masyarakat yang tinggi hanya akan mendorong lebih banyak anak. Ketika pendapatan perkapita meningkat, populasi akan meningkat lebih cepat, sehingga mengurangi pendapatan per kapita sampai batas subsistensi.

Kukrangan teori yang dikemukakan oleh Malthus ini adalah tidak memperhatikan aspek perkembangan zaman dimana pada saat sekarang ini orang-orang sudah mengalami perubahan karena perbuhan zaman pula. Menurut Gimenez yang juga mengkriti teori ini melihat prinsip teori kependudukan Malthus sebagai cara lain borjuis ekonomi menyusun relasi sosial, dan kedua, pada level yang lebih spesifik, jawaban Marx atas pertanyaan prinsip teori kependudukan Malthus adalah prinsip dari angkatan kerja atau pertumbuhan 
relatif penduduk yang dia elaborasi pada wacana dalam analisisnya tentang hukum umum dalam akumulasi kapital.

\section{JB. Say}

Sayy adalah tokoh ekonomi penting Prancis yang lahir di Lyon, Prancis pada tahun 1767 tepat sembilan tahun sebelum The Wealth of Nation dicetak. Say berasal dari keluarga protestan di Prancis selatan yang pindah ke Jenewa dan kemudian menetap di Paris. Say berasal dari Perancis, yang sangat memuja Adam Smith. Say berjasa dalam melakukan kodifikasi pemikiran Smith dan dirangkum dalam bukunya Traite d'Economie Politique pada tahun 1803, dan mendukung faham laissez faire. (Atmanti, 2017). Laissez faire ialah biarkan semua terjadi biarkan ia berjalan dengan wajar tanpa intervensi pemerintah, nanti aka nada tangan maka pasar akan mengalami keefisienan dan keseimbanann. (Parakassi \& Kamiruddin, 2018) Bahkan analisis Say dianggap lebih mendalam dari Smith dan David Ricardo, bahkan Say membangun landasan baru dalam memberikan kontribusi pemikiran ekonomi klasik.

Say kemudian memperbaiki sistem Adam Smithsecara sistematis dan logis. Yang dikenal dengan karyanya hukum Say (Say's Law) yaitu supply Creats its Oven demand dimana setiap penawaran akan menciptakan suatu peermitaannya sendiri. Menurut say di era perekonomian yang bebas dan libera tidak akan terjadi produksi berlebih (over production)yang siifatnya menyeluruh serta pengangguran tidak akan terjadi secara total. Namun kelebihan produksi hanya bersifat sektoral dan dan terbatas. (Purba, Sudarmanto, Syafii, Nugraha, Ahdiyat, \& Umarama, 2020)

Apa yang diungkapka oleh Say ini memang sudah bisa dilihat dalam kehidupan sekarang. Dimana kaum kapitalis dapat menciptakan gaya hidup baru melalui simuklar dan akhirnya membuat masyarakat post modern yang tertipu dengan simuklar tersebut akhirnya membeli produk-produk yang diproduksi dan ditawarkan oleh kaum kapitalis dan mempengaruhi permintaan masyarakat. 
awalnya masyarakat hanya membeli produk dipasaran sesuai fungsinya namun sekarang dengan adanya pemberian label yang dibuat oleh kaum kapitalis membuat banyak masyarakat mebeli apa yang ditawarkan asalkan itu dianggam $=p$ meberikan lebel yang mempunyai kelas dalam masyarakat. 


\section{DAFTAR PUSTAKA}

Atmanti, H. D. (2017). Kajian Teori Pemikiran Ekonomi Mazhab Klasik dan Relevansinya pada Perekonomian Indonesia. JEB17: Jurnal Ekonomi dan Bisnis, 2(02).

Faruq, U. A., \& Mulyanto, E. (2017). Sejarah Teori-Teori Ekonomi.

Ismail, Z. (2012). Teori Ekonomi.

Maiwan, M. (2015). Teori-Teori Ekonomi Politik Internasional Dalam Perbincangan: Aliran Dan Pandangan. J. Ilm. Mimb. Demokr., 15, 109-25.

Muna, T. I., \& Qomar, M. N. (2020). Relevansi Teori Scarcity Robert Malthus Dalam Perspektif Ekonomi Syariah. SERAMBI: Jurnal Ekonomi Manajemen dan Bisnis Islam, 2(1), 1-14.

Parakkasi, I., \& Kamiruddin, K. (2018). ANALISIS HARGA DAN MEKANISME PASAR DALAM PERSPEKTIF ISLAM. Laa Maisyir: Jurnal Ekonomi Islam, 5(1).

Pujiati, A. (2011). Menuju Pemikiran Ekonomi Ideal: Tinjauan Filosofis dan Empiris. Fokus Ekonomi, 10(2), 24459.

Purba, B., Sudarmanto, E., Syafii, A., Nugraha, N. A., Zaman, N., Ahdiyat, M., \& Umarama, A. (2020). Ekonomi Politik: Teori dan Pemikiran. Yayasan Kita Menulis.

Sa'idy, I. B. (2013). Analisis Daya Saing Komoitas Tekstil dan Produk Tekstil Indonesia di Amerika Serikat. Economics Development Analysis Journal , 2, 315.

Subair, S. (2018). RELEVANSI TEORI MALTHUS DALAM DISKURSUS KEPENDUDUKAN KONTEMPORER. DIALEKTIKA, 9(2). 